Case Report

\title{
NASRDA's Experience in Human Capacity Development and Capability Accumulation in Satellite Technology
}

\author{
Francis Dubem Chizea, Reuben Jikeme Umunna*, Ese Oghene Ovie \\ National Space Research and Development Agency, Abuja, Nigeria \\ Email address: \\ chizeaf@yahoo.com(F. D. Chizea), francis.chizea@nasrda.gov.ng(F. D. Chizea), benbenme2k@yahoo.com(R. J. Umunna), \\ reubenumunna@nasrda.gov.ng(R. J. Umunna),oveseovese@gmail.com(E. O. Ovie) \\ ${ }^{*}$ Corresponding author
}

\section{To cite this article:}

Francis Dubem Chizea, Reuben Jikeme Umunna, Ese Oghene Ovie. NASRDA's Experience in Human Capacity Development and Capability Accumulation in Satellite Technology. Advances in Sciences and Humanities. Vol. 5, No. 3, 2019, pp. 70-75.

doi: 10.11648/j.ash.20190503.11

Received: June 4, 2019; Accepted: July 9, 2019; Published: July 23, 2019

\begin{abstract}
The National Space Research \& Development Agency (NASRDA) was created in 1999 to coordinate and oversee all space activities for Nigeria. With little or no human space technology capacity and capability at inception, the agency embarked on an aggressive human capacity building and accumulation mission. From its creation, the agency has been strongly committed to achieving independent satellite development capability. As the agency celebrates its 20 years of existence in 2019, it has emerged as one of the largest space institutions in the African continent - launching five successful satellites of various sizes, all of which involved technology transfers to Nigerian scientists and engineers. NigeriaSat-2 and NigeriaSat-X were two medium Earth Observation satellites launched in 2011 to provide medium resolution imagery to serve the needs of various institutions not only within Nigeria, but also other nations through a constellation of satellites managed by the DMCii, UK. While NigeriaSat-2 was procured from SSTL, NigeriaSat-X served as a training model through which satellite engineering design skills were transferred to Nigerian Engineers from SSTL, UK. Six years after the launch of NigeriSat-2 and Nigerisat-X, a cubesat dubbed "NigeriEduSat-1" was launched from a university-to-university (U2U) collaboration between FUTA, Akure and KIT, Japan. The U2U collaboration, facilitated by National Space Research \& Development Agency, was aimed at improving technology absorption and local diffusion of satellite engineering within the country. This paper reviews strides made by NASRDA in accumulating know-how satellite development and further discusses the various efforts made in building its first satellite independently.
\end{abstract}

Keywords: NASRDA, Satellite Technology, Technology Transfer, Cubesat, Capacity Development, NigeriaSat-X, DMCii

\section{Introduction}

The national space policy, developed in 1998 by National Space Research \& Development Agency, was designed to fulfill the following mandate: Nigeria shall vigorously pursue the attainment of space capabilities as an essential tool for its socio-economic development and the enhancement of the quality of life of its people [1,2]. The Nation shall achieve this through research, rigorous education, engineering development, design and manufacture of appropriate hardware and software in space technology, including transport and payloads, such as satellite, telescopes and antennas for scientific research and applications.

It further states: "Government shall also foster Bi-lateral and international cooperation in all aspects of Space Science and Technology in order to ensure that Nigerian Scientists and Engineers will benefit from global developments in this enterprise".

\subsection{The Reason NASRDA Actively Pursues Indigenous Space Engineering Capability}

Underdevelopment manifests in various forms, some examples of which include; deficiently planned urban areas resulting into heightened susceptibility of disease and 
epidemic spread, inability to predict natural disasters leading to more catastrophic after effects, incessant food shortages, monitoring geographic changes to avoid ethnic clashes, improving agricultural produce and a dearth of valid forecast and prediction data. However, advances made so far in space technology and its application vis-à-vis remote sensing, has the capacity to adequately tackle these challenges that continue to be the basis for prolonged poverty in several developing nations [3]. As an increasing number of local institutions adopt the use space data, Nigeria would in no time migrate to data based decision and policy-making. Indeed, remote data collection is central for an efficient organization and management of terrestrial infrastructures and as such, should serve as a reliable basis for an objective plan of action $[4,5]$.

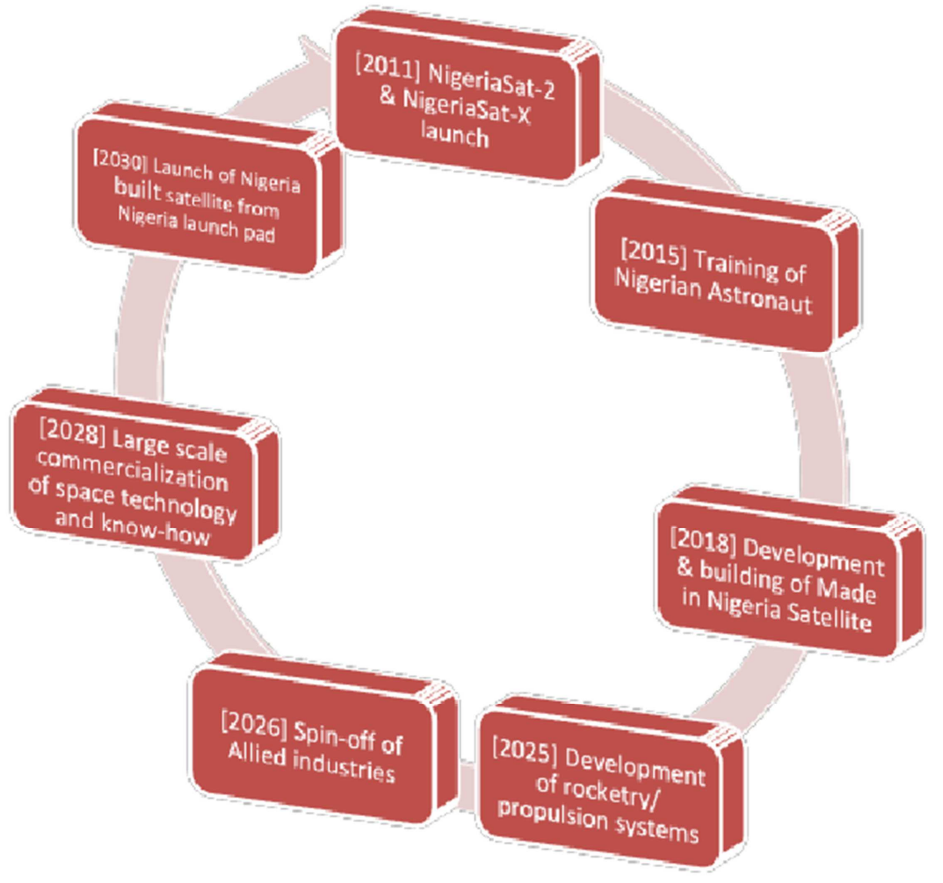

Figure 1. Timeline for 25-year roadmap.

\subsection{NASRDA's Achievements and Goals}

In the 20 years of its existence, NASRDA has launched 5 satellites namely: NigeriaSat-1, NigcomSat-1, NigeriSat-2, NigeriaSat-X, and NigeriaEduSat-1. However, what remains interesting is each of these satellites was developed with a knowledge transfer to Nigerian engineers. The satellites sizes, which range from $1 \mathrm{~kg}$ (NigeriaEduSat-1) to over $1000 \mathrm{~kg}$ (NigComsat-1) depicts the commitment of The National Space Research \& Development Agency in both developing and accumulating human capacity in satellite engineering.

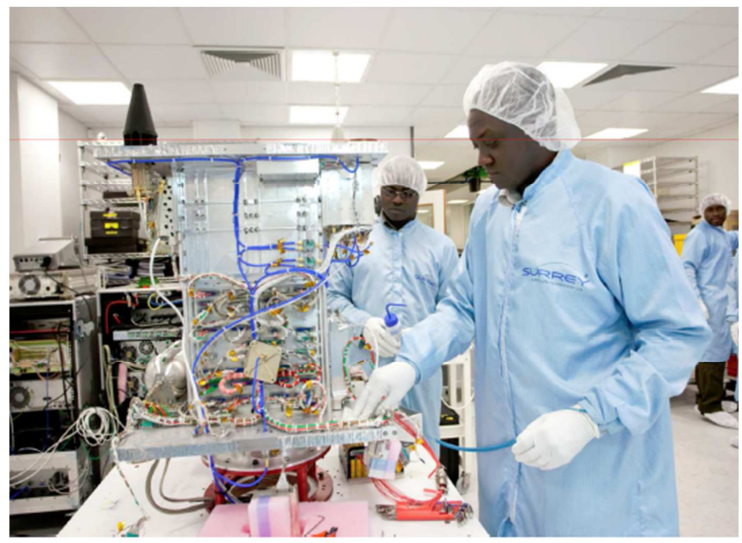

Figure 2. Nigerian Engineers working on NigeriaSat-X at Surrey Satellite Technology Limited.
It is the goal of the agency to develop indigenous capability to design, build, test, and integrate satellites within Nigeria. The technology transfer programs that accompanied each of the 5 national space assets has provided Nigeria with more than 100 engineers trained in various areas of satellite development such as inter alia: all subsystem designs, assembly and testing, ground station operations, and image processing. Acquiring capacity to independently develop a satellite cuts cost and reinforces sustainability of space sciences [6].

\section{Space Emerging Nations}

Space emerging nations are new entrants in the space arena looking at exploiting the peaceful use of space for social \& economic benefit of their nation and mankind [7]. Nigeria falls under this group. It is, however, important to note that the technical capability of nations referred to as Space emerging nations significantly varies [8].

\subsection{Space Technology and Global Innovation Index}

To provide a cursory perspective, the global innovation index (WIPO) and Gross domestic product per capita [9] of 26 space emerging nations [10] were compared in Figure 3. Countries that fare better in global innovation index and 
gross domestic product per capital are nations having a mature local manufacturing and technology ecosystem that is capable of supporting advanced technology such as satellite building and testing. The contrary was also true for underdeveloped and technology disadvantaged nations.

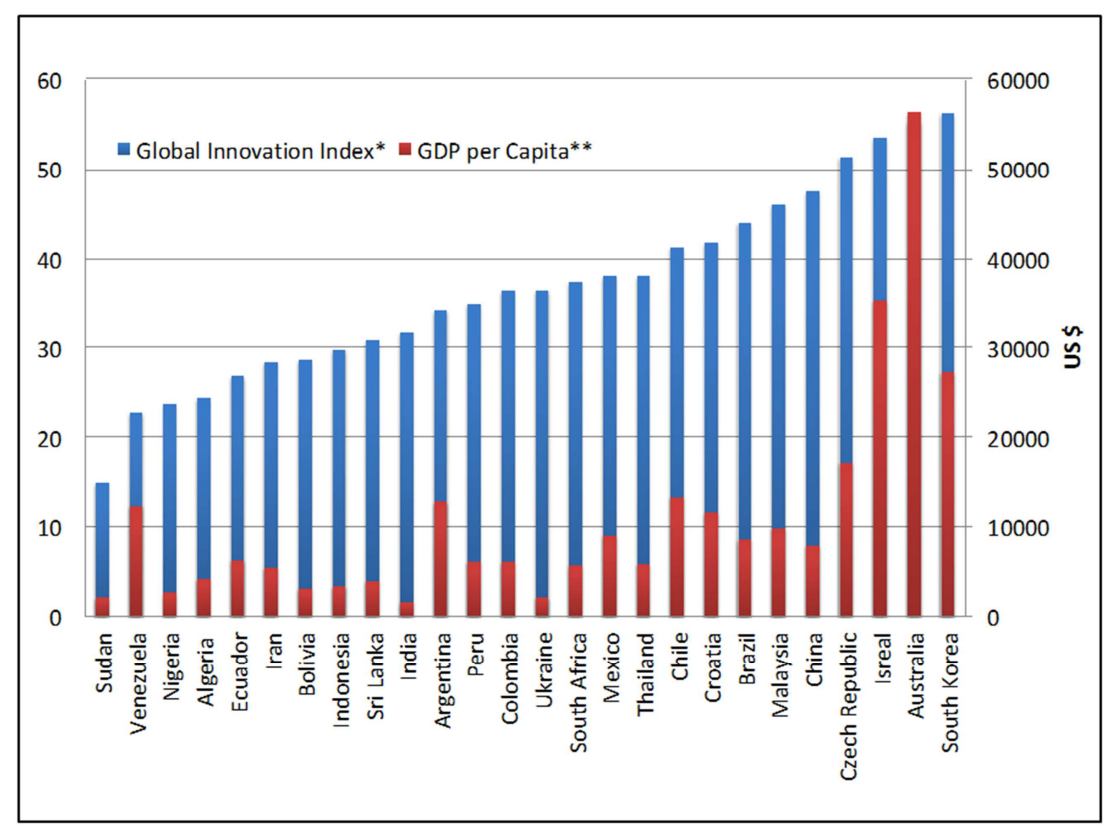

Figure 3. Global Innovation index and GDP per capita of some space emerging nations [3].

\subsection{Technology Disadvantaged Nations}

The most technology immature nations are herein referred to as technology disadvantaged space emerging nations. This is important to note for a number of reasons: satellite development is highly multi-disciplinary and falls under advanced technology category. For less industrialized nations such as Nigeria with less developed manufacturing technology ecosystem, concerted effort and organization is required to achieve indigenous satellite development goal. It is, however, realizable. The term "Technology Disadvantaged nations" as used in this paper refers to nations with under-developed ability to tackle its social problems using locally developed technology. Marboe, Irmgard in [10], shows 2 categories of Space emerging nations - nations that have not demonstrated an independent capacity to develop satellites and others with sufficient human and infrastructural capacity to develop satellites locally.

Table 1. Space Emerging Nations.

More technology-disadvantaged nations
Sudan, Venezuela, Nigeria, Algeria, Ecuador, Iran, Bolivia, Srilanka, Peru,
Colombia, Mexico, Thailand, Chile

\subsection{Absorptive Technological Capacity}

If we agree that technology resides or would reside in people, then we can extend the idea to further state that the success of technology transfer program depends largely on the initial technology absorptive capacity of the engineers and scientists that form the team from the recipient nation. Further, where technology transfer took place in an international location, replicating the absorbed technology in the recipient's home country is largely dependent on how efficiently structured the recipient institution is in readiness to absorb such an advanced technology [11].

Space emerging nations with low technical capability often begin by adopting technology deemed useful to them. However, while that may be a good place to start, experience has shown that for technology-disadvantaged nations, looking at improving their sustainable use of space technology in
Less technology-disadvantaged Nations

Indonesia, India, Ukraine, South Africa, Croatia, Brazil, Malaysia, China, Czech Republic, Israel, Australia, South Korea

decision-making process, technology adoption is insufficient [12]. In line with this, NASRDA is working on strengthening its innovation and Research \& Development departments to improve its technology absorptivity levels [13].

The National Space Research \& Development Agency continues to lean towards a combined technology adoption \& international technology transfer paradigm, in lieu of developing locally robust Research \& Development agency. The need for a technology-disadvantaged space emerging nation such as Nigeria to continuously improve technology absorption capacity along with developing efficient technology diffusion strategy is therefore an imperative.

\section{Technology Transfer Models and Knowledge Diffusion}

Several space agencies from developing nations have in 
the past forged technology transfer collaboration with international partners with the goal of importing high technology such as small satellites technology building know-how [19]. However, whether or not the choice of satellite mission(s) is/are made with respect to national technological maturity remains a difficult question to objectively answer [18].

Kyushu Institute of Technology, Japan through its BIRDS project is collaborating with 5 universities from technology-disadvantaged nations, each simultaneously developing a Cubesat for their country. Such collaborations not only transfer satellite technology skills, but also boost human absorptive capacity of space engineering. The launch of NigeriaEduSat-1 in 2017 benefitted from significant media attention and as result raised huge awareness and interest amongst the university and secondary school students. Its launch also stimulated innovation and strengthened available mechanisms that encourage knowledge diffusion in Satellite technology expertise within Nigeria.

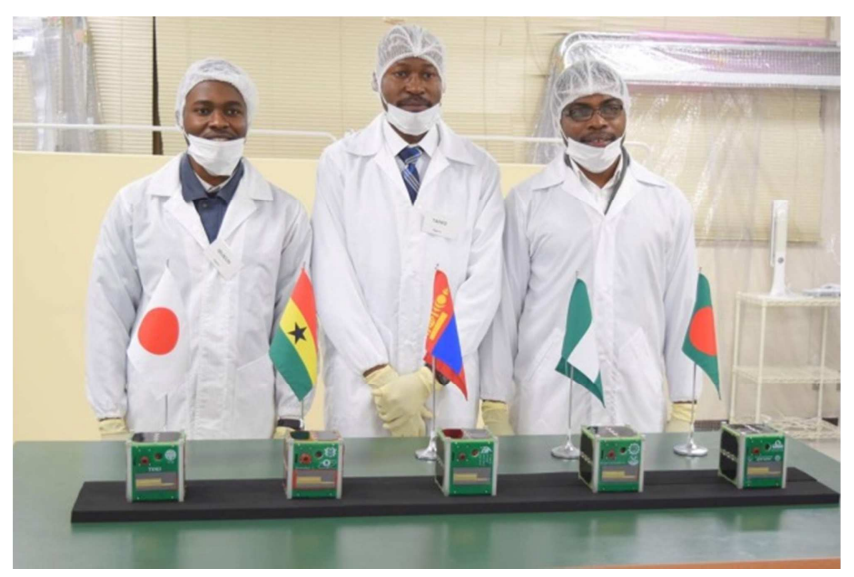

Figure 4. NASRDA \& FUTA Engineers involved in the Technology Transfer program using NigeriaEduSat-1 at Kyushu Institute of Technology, Japan.

\section{Looking Forward: Measuring Human and Infrastructural Capacity to Develop an Indigenous SATELLITE}

Within the last 20 years, National Space Research \& Development Agency has emerged from a few space engineers and scientist to become one of the leading space agencies in Africa. Through various technology transfer program from Nigeriasat-1, NigeriaSat-2, NigeriaSat-X, NigcomSat and recently, NigeriaEduSat-1, the National Space Research \& Development Agency has accrued over 100 satellite engineers and scientists [14].

\subsection{Human Capacity Development Through In-house Training}

Through its in-house training program in various areas of satellite engineering, engineers who directly participated in international technology transfer programs are effectively transferring technical expertise to other engineers and scientists within National Space Research \& Development Agency. The agency has since moved to test and measure the strength of its human capacity while attending to notable areas of weakness as it progresses along its path to achieve independent satellite building capability. However, achieving independent satellite building requires both adequate human and infrastructural capability and capacity. The National Space Research and Development Agency recognizes this and as such is actively exploring cost effective means towards this end.

\subsection{Collaborative Capacity Building Model}

Although the agency is currently working on setting up an Assembly, Integration and Testing (AIT) facility in one of the six centers - the Centre for Satellite technology Development, Abuja, the agency continues to explore cost effective alternatives to make up for the existing infrastructure deficit and still reach its goal of independent satellite building capacity. [15] Presented various technology transfer models, which are captured on Table 2. One of the considered options, option 3, on Table 2, skews towards designing and performing some functional satellite tests within CSTD while other tests requiring elaborate test facilities would be carried out in facility of an international partner. With this model, the National Space Research \& Development Agency can overcome the barriers of acquiring huge and expensive test facility by forging international partnership where specific tests can be carried out.

\subsection{Drawbacks from Foreign Collaborative Model}

However, a major drawback associated with this alternative is the limitation placed by satellite size. Furthermore, when viewed from economic and risk lens, option 3 on Table 2 appears even less appealing especially for satellites above $300 \mathrm{~kg}$. Acknowledging that satellite development is multi-disciplinary, an evaluation of the strength of local manufacturing technology ecosystem necessary to support over $70 \%$ local content contribution in the design and fabrication of an indigenous micro satellite build is pertinent. Failure to reliably evaluate the technology maturity of the local manufacturing ecosystem may lead to costly and lengthy satellite development duration or may even stall the development process.

Table 2. Technology transfer and international partnership models.

\begin{tabular}{lll}
\hline No & Technology Transfer \& collaboration models & Comment \\
\hline 1 & $\begin{array}{l}\text { Design, Assemble, Integrate \& Test satellite within the country with } \\
\text { support from international partners/consultants }\end{array}$ & $\begin{array}{l}\text { An organized \& matured manufacturing ecosystem must be locally } \\
\text { existent. (Any class satellite) }\end{array}$ \\
& $\begin{array}{l}\text { Design specific subsystems locally \& procure others. Assemble, } \\
\text { Integrate \& Test within the developing nation. }\end{array}$ & $\begin{array}{l}\text { Huge investment in facility must be made or availability/location of } \\
\text { such infrastructure within the nation must be known. (Any class } \\
\text { satellite) }\end{array}$ \\
\hline
\end{tabular}




\begin{tabular}{lll}
\hline No & Technology Transfer \& collaboration models & Comment \\
\hline 3 & $\begin{array}{l}\text { Design specific subsystems locally \& procure others. Assemble \& } \\
\text { Integrate within a developing nation \& perform Tests in facility of } \\
\text { international partner }\end{array}$ & $\begin{array}{l}\text { This route favors small, less complex satellites. (Cubesats or low mass } \\
\text { satellites) }\end{array}$ \\
$\begin{array}{l}\text { Design, Assemble, Integrate and Test satellite using facilities in a } \\
\text { developed nation under supervision of engineers of partner } \\
\text { organization }\end{array}$ & $\begin{array}{l}\text { To validate acquired skills, social, cultural and infrastructural blocks } \\
\text { will need to be overcome. (Any class satellite) }\end{array}$ \\
\hline
\end{tabular}

\section{Conclusion}

Good innovative strategy underpins the ability of a nation to adopt new and more effective ways of collecting and exchanging information and data for the purpose of rapid development. To effectively use space technology for socio-economic growth and development, the technology-disadvantaged space emerging nations must not only adopt, but continuously seek new ways to expand their access to space technology and subsequent capacity to use and develop it. This includes developing local and independent competence to build satellites [16].

In the last 20 years of its existence, National Space Research \& Development Agency has built significant satellite building capacity through hands-on technology transfer programs using NigeriaSat-1, NigeriaSat-2, NigeriaSat-X, NigcomSat and recently, NigeriaEduSat-1. With these satellites of varying sizes, more than 100 Nigerian engineers and scientists directly received hands-on training through international partnerships. Even more important, over 200 additionally engineers and scientists have been trained in-house by these pioneer engineers.

In line with NASRDA's 2030 road map - to develop and launch a satellite locally - the agency has moved to measure the strength of its human capacity towards developing an indigenous satellite while identifying existing infrastructural deficits [17]. However, because satellite engineering is an advanced technology and also multidisciplinary, the agency is evaluating and coordinating inputs from the local manufacturing ecosystem, the academia, other research institutions and the private sector across the country to ensure more than $70 \%$ local content contribution towards the realization of Nigeria's first indigenous satellite.

Contextualizing this current push towards sustaining Nigeria's space agency, parallels must be drawn from countries that are our contemporaries in the space business such as Australia, Algeria so as to not proceed in a vacuum [18]. Studying their successes and recorded challenges will be a veritable asset and resource towards placing the Nigerian space journey on surer footing for sustainability.

\section{References}

[1] G. I. AGBAJE, 2008. Current Trends in Nigeria's Space Development Program to Facilitate Geospatial Information (GI) Sharing and Implementation of the NGDI.

[2] Nigeria's Satellite Data Utilization for Sustainable
Development. Environment and Ecology Research 5 (5): 386-394, 2017. J. O. Akinyede; G. I. Agbaje.

[3] United Nations Regional Centre for Space Science and Technology Education in Africa: Achievements, Opportunities, Challenges, and the Future. G. I. Agbaje.

[4] Ian Dowman and Olajide Kufoniyi. Policies for Applying Earth Observation in Africa: An ISPRS Perspective. International Archives of the Photogrammetry, Remote Sensing and Spatial Information Science, Volume XXXVIII, Part 8, Kyoto Japan 2010 .

[5] G. I. AGBAJE. Nigeria in Space - an Impetus for Rapid Mapping of the Country for Sustainable Development Planning. FIG Congress 2010, Facing the Challenges - Building the Capacity Sydney, Australia, 11-16 April 2010.

[6] Building the Appropriate Capacity for Enabling Space Programs in Africa: The Nigerian Experience. 2019. Onuh, Spencer, Chizea, Francis Dubem, Agboola Olufemi, Akoma Henry.

[7] Spyros Pagkratis. Space Policies, Issues and Trends in 2009/2010. ESPI Report 23, June 2010.

[8] M. Ansdell, L. Delgado, D. Hendrickson. Analyzing the Development Paths of Emerging Spacefaring Nations. Opportunities or Challenges for Space Sustainability? April 2011 IAFF 6159: Capstone Research.

[9] The World Bank Group http://data.worldbank.org/indicator/NY.GDP.PCAP.CD. New York: The World Bank Group, 2016.

[10] Marboe, Irmgard. Small Satellites: Regulatory Challenges and Chances. s.l.: Brill, 2016.

[11] Charting the evolution of satellite programs in developing countries The Space Technology Ladder. Danielle, Wood and Annalisa, Weigel. s. 1.: Elsevier, 2011.

[12] A. G. Ojo. Space-Based Technology for Sustainable National Development.

[13] S. Onuh. The Growth and Development of the Nigerian Space Program.

[14] An Overview of the Nigerian Space Programme \& Future Direction. Mohammed, Seidu Onailo. Abuja: NASRDA, 2011.

[15] Capacity Building: A Comparison of International Collaboration at Two Different Levels. Jikeme, Umunna Reuben. Vienna: UNOOSA, 2017.

[16] Data Application Driven Satellite Technology Development In Technology-disadvantaged Space Emerging Nations. Jikeme, Umunna Reuben. Vienna: UNOOSA, 2016.

[17] Cornell University, INSEAD, and the World Intellectual Property Organization. The Global Innovation Index 2015 Effective Innovation Policies for Development. Geneva: World Intellectual Property Organization, 2015. 
Francis Dubem Chizea et al:: NASRDA's Experience in Human Capacity Development and Capability Accumulation in Satellite Technology

[18] Graham Gibbs, 2012. An Analysis of the Space Policies of the Major Space Faring Nations and Selected Emerging Space Faring Nations.
[19] Human Development Report 2016 Human Development for Everyone. United Nations Development Program (UNDP). 